\title{
Cylinder rerouting for lateral extrusion after inflatable penile prosthesis implantation - Surgical technique revision
}

\author{
Paulo Jorge Pinto Pe Leve, João Pedro Cardoso Felício, Pedro Simões de Oliveira, \\ José Manuel Palma dos Reis, Francisco Alves Estrócio Martins \\ Urology Department, Centro Hospitalar Universitário Lisboa Norte, Lisboa, Portugal.
}

\begin{abstract}
Summary Lateral cylinder extrusion is a potential complication of penile prosthesis implantation. Several methods have been proposed for repairing this complication. We present a case where a cylinder re-routing technique, first described by Dr. John Mulcahy, was used and a revision of the literature.
\end{abstract}

KEY WORDS: Penile prosthesis; Lateral extrusion; Surgery.

Submitted 2 March 2020; Accepted 15 March 2020

\section{Introduction}

Implantation of an inflatable penile prosthesis (IPP) is the definitive solution for the treatment of organic erectile dysfunction (ED) in patients who have failed or are unfit for medical treatment and are motivated to pursue continued erectile function and sexual activity (1).

Although IPP patient satisfaction rates are high, $7.5 \%$ of these devices are subject to reoperation, often as a result of mechanical failure. Other common indications for reoperation include patient dissatisfaction, chronic IPP pain, and impending distal or lateral cylinder extrusion. IPP extrusion comprises approximately 5-33\% of reoperations (2). The risk of IPP extrusion appears to be associated with increased time from initial prosthesis placement, prior history of IPP placement, and the presence of corporal fibrosis or deformity.

Several methods have been proposed for repairing IPP extrusion such as closure of the distal corpus cavernosum with replacement of the penile prosthesis in its original position or the use of a patch in order to reinforce the corpus cavernosum (3). If there is no skin erosion this complication can be solved by a cylinder rerouting technique, a technique first described by $D r$. John Mulcahy in 1999 (4). His method has been adopted as an elegant and effective approach that avoids the use of foreign material. We present a case where this surgical approach was used and a revision of the literature.

\section{Clinical case \\ A 67-year-old male patient, with a past history of hyper- tension, type 2 diabetes mellitus, hypothyroidism and ED refractory to medical treatment underwent IPP implantation (AMS $700 C X^{\circledR}$ ) 2 years ago. In the last year he started to complain of inability to deflate the prosthe- sis and penile axis deviation. He was submitted to a prosthesis surgical revision and a cylinder lateral extru-}

sion was identified. He underwent a cylinder re-routing with replacement of both pump and cylinders by the modified Mulcahy technique (4). The surgery was carried out under general anesthesia and lasted 75 minutes. A 14 Fr Foley catheter was inserted into the bladder and was removed 24 hours after the procedure. There were no intraoperative complications. The prosthesis was maintained inflated for 24 hours post operation. The patient was discharged on the first postoperative day. He resumed sexual intercourse 3 months after the surgery. At the moment he is satisfied with the functional outcome. No postoperative complications were documented.

\section{Surgical technique description}

After flexible urethroscopy was performed to ensure that there was no cylinder erosion through the urethra, a subcoronal penile degloving was made and the affected cylinder was exposed (Figure 1A). A lateral longitudinal corporotomy was made over the cylinder. The cylinder was then exposed through the corporotomy (Figure 1B). Then, a penoscrotal incision was made and prosthesis cylinders and pump were removed. The back wall of the fibrotic sheath (pseudocapsule) containing the cylinder was incised transversely, and a new plane of dissection was developed through homolateral corpus cavernosum behind the sheath, distally to the glans (Figure 1C).

A new space in the distal end of the corpus cavernosum was created and dilated to fit the appropriate cylinder caliber. In this manner, the pseudocapsule back wall that formerly comprised the medial wall of the capsule became the lateral aspect of the new capsule. The new cylinder was introduced into the new space in the corpus cavernosum by the penoscrotal approach using a Keith needle and Furlow inserter (Figure 1D). The incision of the fibrotic sheath and corporotomy were then closed with absorbable suture. The cylinder is now protected by 2 though layers comprising the back wall of the fibrotic sheath and the wall of the corpus cavernosum albuginea.

\section{Discussion}

This technique was first described by Mulcahy et al. (4) He reported a series of 14 patients with a follow-up of about 2 years with optimal functional outcomes.

Carson and Noh compared corporoplasty using Mulcahy

No conflict of interest declared. 
Figure 1.

A. Affected cylinder exposition. B. Cylinder retraction through the corporotomy. C. Dissection of the posterior plane beneath the pseudocapsule. $D$. Introduction of the new cylinder in the new cavity by penoscrotal incision.
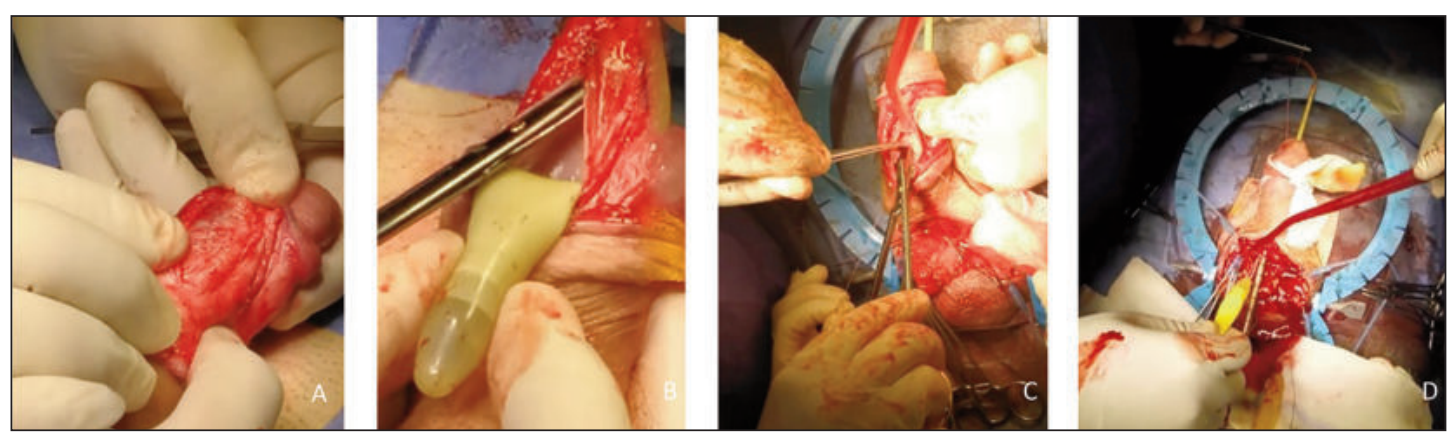

technique with Gore-tex windsock repair based on their experience with 28 patients who presented with impending extrusion. Mulcahy Rerouting technique was performed in 18 men, with the remaining 10 undergoing repair with Gore-tex windsock.

The authors reported that the operative time was shorter for corporoplasty (mean 53 minutes, range 36-81) compared to the windsock repair (mean 90 minutes, range 64-142). There were no infections or recurrences among men underwent distal corporoplasty. One patient who had a windsock repair developed postoperative infection and two had recurrence of extrusion (6 and 18 months, respectively). Functional results were similar in both groups. The authors concluded that distal corporoplasty is an overall superior method because of fewer major complications and reduced surgical time (5).

Shindel et al. developed a transglanular repair method but reported only 6 cases and identified some limitations such as small working space and brisk bleeding of the glans (6).

We opted for the Mulcahy procedure because of its technical simplicity, less operating time, and avoidance of synthetic material which increases the infection risk and surgical cost (1).

Recently, Carrino et al. evaluated 18 consecutive patients with this corporoplasty technique. The operative time was 85 ( \pm 13.1) minutes. No intraoperative complications were reported. One patient (5.55\%) had postoperative infection (7).

This technique is a simple and safe procedure in the treatment of lateral cylinder extrusion when the prosthetic material is not exposed to the outside surface. It also avoids the costs of the use of additional artificial material.

\section{References}

1. Levine LA, Becher E, Bella A, et al. Penile prosthesis surgery: current recommendations from the International Consultation on Sexual Medicine. J Sex Med. 2019; 13:489-518.

2. Fuentes JL, Yi YA, Davenport MT, et al. Long-term sequelae of inflatable penile prosthesis: clinical characteristics of patients who develop distal cylinder tip extrusion. Transl Androl Urol. 2020; 9:38-42.

3. Stember DS, Kohler TS, Morey AF. Management of perforation Injuries during and following penile prosthesis surgery. J Sex Med. 2015; 12 (Suppl 7):456-461.

4. Mulcahy J. Distal corporoplasty for lateral extrusion of penile prosthesis cylinders. J Urol. 1999; 161:193-195.

5. Carson CC, Noh CH. Distal penile prosthesis extrusion: treatment with distal corporoplasty or Gortex windsock reinforcement. Int J Impot Res. 2002; 14:81-4.

6. Shindel AW, Brant WO, Mwamukona K, et al. Transglanular repair of impending penile prosthetic cylinder extrusion. J Sex Med. 2010; 7:2884-90.

7. Carrino M, Chiancone F, Battaglia G, et al. Distal corporoplasty for distal cylinders extrusion after penile prosthesis implantation". Actas Urol Esp. 2016; 84:38-39.

\section{Correspondence}

Paulo Jorge Pinto Pe Leve, MD (Corresponding Author)

paulo.peleve@gmail.com

Rua Jaime Cortesão, n 21, 7050-250 Montemor-o-Novo (Portugal)

João Pedro Cardoso Felício, $M D$

Praceta Fernando Valle, n ${ }^{\circ} 8^{\circ} \mathrm{B}, 1750-489$ Lisboa (Portugal)

Pedro Simões de Oliveira,MD

pedrosimoesdeoliveira@gmail.com

Rua Maria Lamas, 2, $9^{\circ}$ direito, 1500-438 Lisboa (Portugal)

José Manuel Palma dos Reis, MD

jpalmareis@gmail.com

Francisco Alves Estrócio Martins, MD

faemartins@gmail.com

Avenida Professor Egas Moniz, 1649-028 Lisboa (Portugal) 